Gynäkol Rundsch 1989;29(Suppl 1):96

\title{
Autorenregister und Donatoren
}

Baer, S. 23 Böckle, F. 4 Bretscher, J. 68 Bronz, L. 55 Engeler, V. 17,35 Keller, K. 35 Keller, P.J. 2 Maroni, E. 63

Müller,R. 60 Neuenschwander, F. 71 Rageth,J.C. 75 Schmid,J. 29 Schreiner, W.E. 23, 35, 60, Steiner, R. 1,35 Stoll,W. 44 Wight, E. 60

Für die grosszügige Unterstützung in der Durchführung des Symposiums danken wir folgenden Firmen:

Beecham AG, 3174 Thörishaus Ciba-Geigy AG, 4002 Basel CilagAG, 8201 Schaffhausen Farmitalia Carlo Erba AG, 6300 Zug F. Hoffmann-La Roche \& Co. AG, 4002 Basel Inpharzam SA, 6814 Cadempino Johnson \& Johnson AG, Ethicon Division, 8957 Spreitenbach Medinova AG, 8052 Zurich

Mundipharma AG, 4002 Basel Novo Industrie (Pharma Schweiz), 8032 Zurich Organon AG, 8808 Pfáffikon Rhône-Poulenc Pharma Schweiz AG, 8800 Thalwil Sandoz-Wander Pharma AG, 3001 Bern Schering AG, 8010 Zurich Winthrop AG, 4002 Basel WyethAG, 4010 Basel 